\title{
Praxeological Change and the Density of Rational Numbers: The Case of Pre-service Teachers in Denmark and Indonesia
}

\author{
Zetra Hainul Putra ${ }^{1,2^{\star}}$ \\ ${ }^{1}$ University of Copenhagen, Department of Science Education, Copenhagen, DENMARK \\ ${ }^{2}$ University of Riau, Faculty of Teacher Training and Education, Pekanbaru, INDONESIA \\ Received 13 September 2018 - Revised 7 November 2018 - Accepted 20 December 2018
}

\begin{abstract}
The present study aims to introduce the notion of praxeological change, developed based on the Anthropological Theory of the Didactic, to describe a necessity of changing mathematical praxeologies when passing from natural to rational numbers. It is applied to study and compare Danish and Indonesian pre-service teachers' (PSTs) knowledge of the density of rational numbers. They work in pairs to solve and discuss a hypothetical teacher task, which involves both mathematical and didactical tasks, related to the density of rational numbers. The findings highlight significant differences of the mathematical and didactical knowledge which are shared by the Danish and Indonesian PSTs. In particular, the Danish PSTs are more successful than the Indonesian PSTs in proposing didactical praxeologies to support pupils' praxeological change. They use the mathematical idea of converting fractions into decimals or vice versa and representing fractions and decimals on the same number line, while the Indonesian pairs tend to suggest pupils to order fractions and decimals based on the ordering properties of natural numbers.
\end{abstract}

Keywords: praxeological change, anthropological theory of the didactic, hypothetical teacher task, density of rational numbers

\section{INTRODUCTION}

An extensive amount of research on teachers' knowledge about rational numbers exists (An, Kulm, \& Wu, 2004; Depaepe et al., 2015; Ma, 1999; Zhou, Peverly, \& Xin, 2006). Among the general observation is that teachers may successfully solve a mathematical task dividing one fraction by another, using a standard procedure, and still be unable to explain why it works or what such an operation could be used for; and that this translates into teaching focused on procedures with little meaning. Moreover, the set of rational numbers has properties, such as density, which make it quite different from the set of natural numbers, and which are difficult to understand even for teachers. For instance, Widjaja, Stacey, and Steinle (2008) found that Indonesian pre-service teachers (PSTs) had severe difficulties with the density of the set of finite decimals. The teachers overgeneralized their knowledge about whole numbers to the case of decimal numbers.

Many previous studies (McMullen, Laakkonen, Hannula-Sormunen \& Lehtinen; 2015; Prediger, 2008; Vamvakoussi, Christou, Mertens \& Van Dooren, 2011; Vamvakoussi \& Vosniadou, 2004, 2010) have argued that there is conceptual change involved in the process of passing from natural to rational numbers. This means that learning rational numbers requires one to change one's prior conceptions of something, like numbers, in order to be compatible with a new mathematical situation - they cannot simply be adapted but need more fundamental revision. However, the change required to pass to rational numbers is not only about concepts, but also about practices. Vamvakoussi and Vosniadou (2004), for instance, studied students' knowledge of the structure of the set of rational numbers from the conceptual change approach, and analysed students' answers in terms of discreteness-density categories of conceptual knowledge. To understand these categories better, and indeed to model students' knowledge in a more complete way, one needs to have a theoretical model that could describe the

(C) 2019 by the authors; licensee Modestum Ltd., UK. This article is an open access article distributed under the terms and conditions of the Creative Commons Attribution License (http://creativecommons.org/licenses/by/4.0/). \zetra.hainul.putra@lecturer.unri.ac.id zet22boy@yahoo.co.id (Correspondence) 


\section{Contribution of this paper to the literature}

- This study introduces the notion of praxeological change as a theoretical model developed within the anthropological theory of the didactic to describe the change of human practice and theory from natural to rational numbers.

- The praxeological change is used to study and compare Danish and Indonesian pre-service teachers' mathematical and didactical knowledge of the density property of rational numbers.

- This study would contribute to developing a model to study teachers' individual and collaborative mathematical and didactical knowledge.

change of practice and theory from natural to rational numbers - in other words, respondents' mastery of theoretical ideas such as density needs to be related with their grasp of practical tasks, like adding or ordering two numbers.

To achieve such a more detailed and complete model of teachers' knowledge, this study is based on the Anthropological Theory of the Didactic (ATD) (Chevallard, 1992, 2006, 2007), that emphasises mathematical knowledge as a human practice consisting of two related components than can be modelled into a praxeology (the praxis or the practical block and the logos or theoretical block). To be able to use the praxeology to describe this collective change, and circumvent the individual/cognitive ideas related to the term "conceptual change", we introduce the notion of praxeological change to describe a change of knowledge that concerns not only concepts in isolation but a coherent whole of practice and theory.

In the present study, we introduce the theoretical framework and in particular the new idea of praxeological change that students (and sometimes also pre-service teachers (PSTs)) need to achieve in order to fully master the practices and theory of rational numbers. Concretely, we shall study and compare Danish and Indonesian PSTs' mathematical and didactical knowledge related to the density of rational numbers, as an indicator of the extent to which they have themselves achieved the praxeological change from natural to rational numbers, and of the extent to which they could support pupils to accomplish this change. One motivation to compare Danish and Indonesian PSTs on this specific (and somewhat advanced) aspect of primary school mathematics and didactics is that it might help to explain the gap between Danish and Indonesian pupils' achievements in international surveys like TIMSS and PISA (Mullis, Martin, Foy \& Hooper, 2016; OECD, 2016). Indeed, it is generally assumed that pupils' mathematical achievement is strongly related to their teachers' mathematical and didactical knowledge for teaching (Hill, Rowan \& Ball, 2005).

\section{PRAXEOLOGICAL CHANGE}

The anthropological theory of the didactic (ATD) is a research programme in mathematics education research that has been developed over more than three decades (Chevallard, 1992, 2006, 2007). ATD emphasises and models the institutional dimension of mathematical and didactical activities explicitly (Bosch \& Gascón, 2014). Mathematical practices and knowledge are considered as situated in institutions and are modeled in terms of mathematical praxeologies. The practices and knowledge of an institution related to the teaching and learning of mathematical praxeologies are modeled in terms of didactical praxeologies.

The notion of praxeology is in fact assumed to describe any kind of human practices and knowledge (Chevallard, 1999, 2006). The praxeology consists of two interrelated components, namely praxis and logos. The praxis or practical block consists of a type of tasks $(\mathrm{T})$ and associated techniques $(\tau)$, and the logos or the theoretical block consists of a technology $(\theta)$ and a theory $(\Theta)$. The techniques function to solve some tasks of a given type. The technology is used to justify the techniques, and then a theory serves to explain and unify a set of technologies.

In a mathematics teaching and learning situation, a teacher is faced with didactic tasks. Bosch and Gascón (2014) have argued that a didactical praxeology is generated by the task of making certain mathematical praxeologies available to students. Teachers' knowledge is thus modeled in terms of didactical techniques, technology and theory (Barbé, Bosch, Espinoza, \& Gascón, 2005; Rodríguez, Bosch \& Gascón, 2008), which are by definition closely linked to mathematical praxeologies.

In the context of elementary mathematics, Arithmetic is one of the important domains to be taught by the teachers and learned by the pupils. There are many intriguing mathematical and didactical praxeologies in this domain. For instance, in the early years of elementary education, common mathematical praxeologies are around natural number properties. One of the mathematical tasks is to find how many natural numbers one can find between 1 and 10. A technique to deal with this task is counting from 1 to 10 . A technological discourse justifying this technique is that 2 is the successor of 1,3 is the successor of 2, and so on. The principle (or axiom) for ordering the set of natural numbers is the theory which justifies this technology. A didactical task could be to plan a learning activity for pupils to find how many numbers there are between 1 and 10. An example of the didactical technique is to let pupils practice with some concrete materials such as number blocks. A teacher may argue that the concrete 


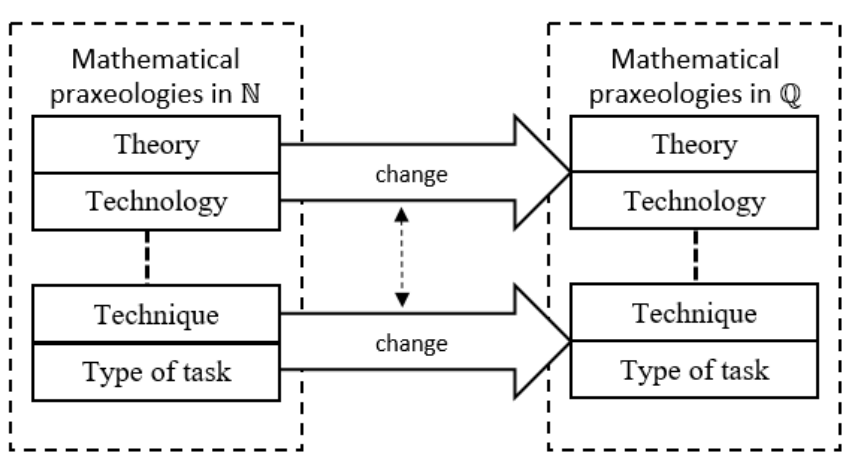

Figure 1. A model of praxeological change from natural to rational numbers

materials help pupils to count the numbers easily from 1 to 10 (a didactic technology), and in fact, principles of using concrete objects to represent natural numbers can be seen as an (informal) didactical theory to justify this technology.

Shifting from natural to rational numbers (often represented as fractions and decimals in the context of elementary school mathematics), pupils need to reconstruct and deconstruct their mathematical praxeologies. In this process, they have to develop new mathematical practices, technologies, and theories, as they will not succeed if they just adopt and extend previous mathematical praxeologies related to natural numbers. This is not only something which is to be done by the individual pupil, but it is a process in which the praxis and knowledge blocks of all pupils have to adapt, over a period of time, to a new institutional standard of praxeologies related to numbers. In general, this process is called as praxeological change; that is an institutional deconstruction and reconstruction of a set of new praxeologies in order to cope with an extended set of objects or tasks, when the old praxeologies only apply to a part of these and cannot be extended or generalised to apply to them all. For instance, there is no way to extend the arithmetic founded on counting techniques to rational numbers. The change concerns not only the technical level but also the theoretical one: many notions which are important at the early natural number theory, such as odd and prime numbers, successor numbers, reverse number (e.g., 21 as the reverse of 12), etc., cannot be extended to the rational numbers.

To give such a more detailed and definite case where praxeological change is needed, one can consider the mathematical task of finding rational numbers between $\frac{2}{5}$ and $\frac{3}{5}$. Mathematical techniques to solve such a task of "finding the numbers in between" have to be changed relative to what was previously done, and they are not just simply an extension of the old mathematical techniques for natural numbers. Even though one may notice that rational numbers are topologically discrete, their order structure makes them "dense in itself". It means that between two successive rational numbers such as $\frac{2}{5}$ and $\frac{3}{5}$, one can find other rational numbers - in fact, infinitely many rational numbers. The praxeologies related to the arithmetic mean can be used to prompt pupils to perceive the concept of density (Brousseau, 1997; Vamvakoussi, \& Vosniadou, 2004). In fact, between two rational numbers $x$ and $y$, one can find a new rational number $w_{0}=\frac{x+y}{2}$, repeat the procedure for the new interval $\left[x, w_{0}\right]$ to find $w_{1}$ between $x$ and $w_{0}$, and so on. This mathematical technique leads one to infer that there are infinitely many numbers between two rational numbers. A similar technique to show the density of rational numbers is based on equivalence classes of rational numbers. For instance, to find other rational numbers between $\frac{2}{5}$ and $\frac{3}{5}$, one can extend fractions to find the equivalent value for both numbers, $\frac{2}{5}=\frac{4}{10}$ and $\frac{3}{5}=\frac{6}{10}$, and then one can see that $\frac{5}{10}$ is between the two rational numbers and repeat this technique until one realises that there are infinitely many rational numbers between the two rational numbers. Yet another possibility is to convert fractions to decimals (or vice versa), for instance, to find 0.5 between 0.4 and $0.6,0.41$ between 0.40 and 0.50 , etc. This reinforces the theory of representations of rational numbers and the practice of changing between them. Consequently, the change of theory (for instance on how numbers are represented) needs to be coordinated with the change of practice. The praxeological change from natural to rational numbers can be illustrated on Figure 1.

The necessity of pupils (mathematical) praxeological change also has consequences for teachers' didactical praxeologies, as they need to face the didactic task to support pupils' praxeological change. In practice, teachers in many countries struggle themselves with more advanced sides of the praxeologies involved in the successive construction of numbers (natural $\Rightarrow$ decimal $\Rightarrow$ rational $\Rightarrow$ real). Mathematical and didactical tasks involving the density of rational numbers can be seen as such "advanced sides" and used to study teachers' praxeologies and praxeological change, because they require the teachers to reconstruct and deconstruct their mathematical and didactical knowledge as explained above. 


\section{BACKGROUND AND RESEARCH QUESTIONS}

There are quite extensive studies on pupils' and teachers' knowledge on the density of rational numbers (Christou, 2015; Depaepe et al., 2015; Durkin \& Rittle-Johnson, 2015; McMullen et al., 2015; Stacey, Helme, Archer, \& Condon, 2001; Widjaja et al., 2008; Vamvakoussi et al., 2011; Vamvakoussi \& Vosniadou, 2004, 2010; Van Hoof, Verschaffel, \& Van Dooren, 2015). Most studies show that pupils and teachers often over-generalise the discrete nature of natural numbers to rational numbers. Vamvakoussi and Vosniadou (2004) have argued that the idea of discreteness is the fundamental presupposition that constrains pupils' knowledge of density. The pupils only see a finite number of different numbers between any two given rational numbers. A similar result is also found in the study of Belgian PSTs: they had only developed an intermediate level of understanding the notion of density, and assume that there was a finite number of different numbers between two given rational numbers (Depaepe et al., 2015).

McMullen et al. (2015) have found that very few pupils exhibit well-developed mathematical knowledge about the density of rational numbers after having attended one-year instruction on decimals and fractions. One reason for pupils' difficulties about the density of rational numbers is that pupils do not get any direct instruction, involving mathematical notions that can be useful to handle this difficult subject. Actually, they learn that fractions can always be further broken down, such as dividing a "pizza" diagram in smaller units, but this is not sufficient for them to grasp the mathematical phenomenon of the density of rational numbers.

$\mathrm{Wu}$ (2014) has argued that the learning of fractions (or rational numbers), including the density of rational numbers, cannot be promoted by emphasizing only the pedagogical, cognitive, or some other learning issues because, above all else, the mathematical development of the subject must be accorded a position of primacy. The education community should begin to accept this fact that there is a need for a "good reference model" which is consistent with a formal theory of current mathematics, such as a rational number is a point on a number line (Behr, Lesh, Post \& Silver, 1983), and it can be used to support pupils' understanding the density properties of rational numbers. In addition, it may be important to investigate the official curricula of schools in relation to such a model, and begin to question if the latter is altogether coherent. Even though one can certainly question whether Wu's idea of teaching this definition in elementary schools is realistic, much research (e.g. Ma, 1999) points to the fact that teachers also do not know these well, and share with pupils more the informal - in part misleading - ideas of what fractions (and more formally, rational numbers) are.

A good reference model needs to be developed in order to examine the ways in which pupils and their teachers perceive the set of rational numbers between two given rational numbers. Stacey et al. (2001) have suggested to use linear model representations such as number lines to support pupils to develop the density of rational numbers. They emphasise that the number line representation has a structure where one can see more rational numbers in between two given rational numbers. One also can see that two or more representations of rational numbers can be located in the same position, and this can lead one to grasp the equivalence classes of rational numbers. On the other hand, teachers who do not realise this fact may put fractions and decimals in two different number lines, and locate them like ordering whole numbers on the number lines.

\section{Teacher Education Programmes in Denmark and Indonesia}

The study was conducted in two different countries, Denmark and Indonesia, that have both similar and different characteristics of teacher education programmes. The teacher education in Denmark is decentralised, but in accordance with common legislation (Rasmussen \& Bayer, 2014). The teacher education programmes for elementary schools (to teach grade 1-6) and lower secondary schools (to teach grade 4-10) are conducted in seven University Colleges. Meanwhile, the teacher education programme for upper secondary schools takes place in universities. The teacher education program is a four-year professional bachelor degree programme (240 European Credit Transfer System [ECTS]). Every PST has to choose at least two main subjects, with three main subjects being the norm (Ministry of Higher Education and Science, 2015). The total ECTS for the main subjects are around 140 ECTS, and mathematics for grade 1 to 6 or grade 4 to 10 is one among several main subjects that can be selected by PSTs. The mathematics/mathematics education courses to be taught in the programmes are decided by Ministry of Higher Education and Science (2015), but the content of the education is decided by each individual university college (Winlsøw \& Durrand-Gurrier, 2007). There are four courses related to mathematics and mathematics education (40 ECTS/ 16.7\%), namely 1) Learning mathematics, numbers, and processes in arithmetic (plus algebra for grade 4 to 10), 2) Teaching mathematics and geometry, 3) Assessment and stochastics, and 4) Pupils with special needs and mathematical tools.

In Indonesia, the teacher education system is also decentralised. The programme for elementary teacher education (to teach grade 1-6) is offered by 267 universities/university colleges, and the mathematics teacher education programme (to teach grade 7-12) is offered by 268 universities/university colleges (The Indonesian national accreditation agency for higher education [BAN-PT], 2017). Specifically, in Riau province where the data 
for this study are collected, there are 5 elementary and 6 mathematics teacher education programmes. The teacher education program is a four-year professional bachelor degree programme (144 credits). The teacher education programmes are under the Ministry of Research, Technology, and Higher Education (Ristekdikti), but there is no a specific guideline for them (Ristekdikti, 2016). So, every programme has to develop its own curriculum and decide the mathematical contents to be taught. For instance, the Elementary School Teacher Education program at the University of Riau, provides 7 courses (18 credits/12.5\%), namely 1) Fundamental mathematics for elementary schools I, 2) Fundamental mathematics for elementary school II, 3) Mathematics education for the lower grades of elementary schools, 4) Mathematics Education for the upper grades of elementary schools, 5) Statistics for education, 6) Capita Selecta mathematics (e.g. problem solving and modelling in mathematics) and, and 7) Indonesian realistic mathematics education (Teacher Education for Elementary School Study Programme University of Riau [Prodi PGSD UR] , 2017). The last two courses are optional, but PSTs have to choose one of them.

\section{Research Questions}

Taking into account the discussion above, this paper will contribute to the knowledge about the nature of teachers' mathematical and didactical praxeologies related to the density of rational numbers, taking the comparison of Danish and Indonesian PSTs as a case. The second aspect that we emphasize is about their collective work to support pupils' praxeological change from natural to rational numbers. We elaborate this aspect on the method section. So, this study will address the following research questions:

$\mathbf{R Q}_{1}$ : What are the differences between Danish and Indonesian PSTs' mathematical and didactical praxeologies related to the density of rational numbers?

$\mathbf{R Q}_{2}$ : To what extent have they themselves realised the praxeological change?

$\mathbf{R Q}_{3}$ : What didactical ideas to support pupils' praxeological change on the density of rational numbers can PSTs work out collectively? Is there any difference between Danish and Indonesian PSTs?

\section{METHODS}

This study was based on ATD, specifically praxeologies, through designing hypothetical teacher tasks (HTTs) to investigate and compare Danish and Indonesian PSTs' knowledge on rational numbers. The notion of HTTs is firstly introduced by Winsløw and Durand-Guerrier (2007) and Durand-Guerrier, Winsløw, and Yoshida (2010) to investigate how PSTs interact with a teaching situation which could reasonably arise at school. The mathematical contents of the situations are elementary, in the sense that they can be handled by elementary mathematical and didactical knowledge. In the context of the density of rational numbers, a problem, such as pupils assume that there is only one fraction between $\frac{2}{5}$ and $\frac{4}{5}$, namely $\frac{3}{5}$, can be seen as a potential situation that may occur in the course of teaching. PSTs need to have adequate and relatively well-developed praxeologies on rational numbers in order to propose appropriate didactical praxeologies on the density of rational numbers.

\section{HTT about the Density of Rational Numbers}

The HTT about the density of rational numbers is one among 5 HTTs designed for a comparative study of PSTs' knowledge of rational numbers (Putra \& Winsløw, in press). All HTTs consist of two kinds of tasks, mathematical and didactical tasks. The HTT about the density of rational number is designed based on the literature, which has been discussed in the previous section, showing that many pupils and also teachers have severe difficulties to grasp the density property of rational numbers. It is set to enable PSTs to work individually for the mathematical task (question a) and then deploy their mathematical knowledge to address the didactical task (question b) during the discussion. The detailed HTT given to PSTs is described as follows:

You first ask fifth-grade pupils to discuss how many numbers there are between $\frac{2}{5}$ and $\frac{4}{5}$, and how many numbers there are between 0.4 and 0.8 .

Then, they say that there is only one number between $\frac{2}{5}$ and $\frac{4}{5}$ namely $\frac{3}{5}$; they also say 3 numbers between 0.4 and 0.8 .

a. How do you interpret this claims? (to be solved individually within 3 minutes).

b. Explain your ideas to teach these pupils? (to be discussed and solved in pairs within 5 minutes).

\section{Participants}

The participants are 32 Indonesian PSTs (16 pairs) from the Elementary School Teacher Education study program from a University in Riau province, Indonesia and 31 Danish PSTs (14 pairs and one group of three PSTs) from four teacher training colleges in Denmark. All the Indonesian PSTs were fourth-year students and had 
completed all courses on mathematics and mathematics education. The course of mathematics education for upper grades of elementary schools was taken in the second year of their study in which teaching and learning rational numbers, in the sense of fractions and decimals, was the main part of that course. Meanwhile, the Danish PSTs were from different years of study, but most of them were third and fourth-year students. Although they had not completed all courses on mathematics and mathematics education, all of them have already got the instruction related to rational numbers. This topic is part of the course about learning mathematics, numbers, and processes in arithmetic that was given in the first-year study. So, we assume that they may not have a problem to understand the HTT, and they could also use their prior mathematical knowledge about numbers.

\section{Procedures and Data Collection}

The HTT about the density of rational numbers was written in English, and then it was translated into Indonesian by the researcher and into Danish by a Danish graduate student in didactics of mathematics. Two Indonesian and two Danish researchers/educators checked the consistency of the Indonesian and Danish translation, respectively. Then, the HTT about the density of rational numbers, along with the other HTTs on rational numbers, was tested to Indonesian and Danish PSTs from January 2016 to March 2017.

The data consists of PSTs' individual written answers and video recordings from the discussions carried out in pairs. For the video recordings, the researcher did the Indonesian transcription, and the Danish graduate and Ph.D. students in didactics of mathematics did the Danish transcription. The data were mostly transcribed into English in order to let the data be visible and to be discussed with other didactics mathematics researchers in that area.

\section{Data Analysis: An a priori analysis of HTT}

First, an a priori analysis of the HTT about the density of rational numbers is presented through describing some possible reference models based on praxeologies, called praxeological reference models (PRM). Then, the PRM is used as a broader guideline to an a posteriori analysis of actual data from individual and collective work.

Two possible types of tasks can be modelled from the HTT; 1 ) a mathematical task (from question a), and 2) a didactical task (from question b). the types of tasks can be written, respectively, as follow, and the preliminary $a$ priori analysis has been presented in Putra (2016).

$\mathrm{T}_{\mathrm{a}}$ : given two different fictitious pupils' answers about how many numbers between two fractions and between two decimals, then interpret these answers.

$\mathbf{T}_{\mathbf{b}}$ : given the tasks of type $\mathrm{T}_{\mathrm{a}}$ together with the pupils' answers to these tasks, identify methods to teach the pupils?

In general, possible mathematical praxeologies can be illustrated based on three categories; namely discreteness, discrete-density, and density (Vamvakoussi, \& Vosniadou, 2004). PSTs who apply directly a praxeology for natural numbers to rational numbers are said to be captured in a discrete praxeology, as an evidence of a missing or incomplete praxeological change. They consider that there is only one numbers between $\frac{2}{5}$ and $\frac{4}{5}$, but there are three numbers between 0.4 and 0.8 . They do not realise the equivalence between $\frac{2}{5}$ and 0.4 or $\frac{4}{5}$ and 0.8 . PSTs who consider that the density of rational numbers depends on how such numbers are represented are said to have a discretedenseness praxeology. For instance, they may say that there are infinitely many numbers between two decimals but not between two fractions, arguing in the first case that they could easily add many 0s to the digits after a comma, but in the second case operating only with one denominator. Finally, having a denseness praxeology means that PSTs have successfully accomplished the praxeological change, to the point of mastering density of rational numbers regardless of their representation. They then successfully figure out that there are infinitely many numbers between two different rational numbers, no matter the representations they appear in. They are able to use different representations of fractions: $\frac{2}{5}=\frac{4}{10}=\frac{400}{1000}$, etc. and decimal numbers: $0.4=0.40=0.400$, etc., and to include the intermediate elements. They also know the equivalence between $\frac{2}{5}$ and 0.4 or $\frac{4}{5}$ and 0.8 . The flexible use of the fractional and decimal representations of rational numbers becomes an important element of the practice to grasp the density property of rational numbers.

In relation to the task of type $\mathrm{T}_{\mathrm{a}}$, PSTs may provide different interpretations based on their judgment of the pupils' fictitious given answers. Some PSTs may agree with pupils' answers, so they consider to apply mathematical techniques using whole number reasoning to rational numbers. On the other hand, some PSTs may realise that mathematical techniques used for natural numbers, such as counting, has to be changed when they work with fractions or decimals. For example, PSTs recognise that the pupils' answers are incorrect because the pupils just notice the mathematical task is about ordering fractions with a common denominator or decimals with one-digit, so they suggest a mathematical technique such as converting fractions to decimals or vice versa, partitioning the interval, and arithmetic means. Technological discourse underlying the technique, such as converting fractions to 
decimals, concerns the passage between different representations of rational numbers, including the passage between decimals and fractions, and between equivalent fractions.

PRM for the didactical techniques to the task of type $\mathrm{T}_{\mathrm{b}}$ is developed based on how PSTs interpret the pupils' given answers. PSTs may consider that their answers are correct, and then they probably instruct pupils using ordering numbers. On the other hand, PSTs who consider pupils' given answers as incorrect may propose to explain one of the appropriate mathematical techniques, or they may try to represent both tasks into a number line to show that the two given pairs of fractions and decimals have identical value. Meanwhile, a possible technological-theoretical discourse underlying this didactical technique proposed by PSTs is based on their belief that the pupils need a concrete mathematical task which brings out this point.

\section{FINDINGS}

\section{The Praxeological Analysis of Danish and Indonesian PSTs' Written Answers}

The Danish PSTs' written answers have more emphasis on technological discourses than on direct judgment for pupils' answers to the tasks of type $\mathrm{T}_{\mathrm{a}}$. Twenty-seven Danish PSTs provided at least one technology behind pupils' given answers and misconceptions, and the most common didactical technology for giving such answers was that pupils just considered fractions and decimals as number sequences. For instance, one PST wrote as follows:

When the pupils see numbers between $\frac{2}{5}$ and $\frac{4}{5}$ I assume that they see the number, $\frac{3}{5}$, as part of the sequence of numbers with nominators 2,3 , and 4 . Between 0.4 and 0.8 , they similarly see 3 number namely $0.5,0.6$, and 0.7 (DS4c).

Some Danish PSTs claimed that a lack of knowledge about numbers in general could be a possible reason why they assumed principles for natural numbers would also hold "in general". The pupils should notice that decimals and fractions are representations of rational numbers. Indeed, using a mathematical technique to convert fractions to decimals, they argued that pupils could see that $\frac{2}{5}$ equals to 0.4 , and $\frac{4}{5}$ equals to 0.8 . While, five Danish PSTs stated that there are many numbers between two fractions and between two decimals. They support this argument through a technological discourse of equivalent value of two different rational number representations.

A few Danish PSTs provided inappropriate examples to expose their mathematical knowledge. For instance, one PST gave an explanation

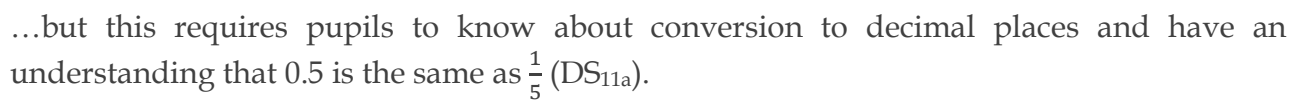

$\mathrm{DS}_{11 \mathrm{a}}$ did not notice the different value or size of these numbers, and she just turned the digit behind the comma into the denominator.

The Indonesian PSTs' written answers, on the other hand, are more explicit on their judgment than on giving technological discourses for the pupils' given answers to the task of type $\mathrm{T}_{\mathrm{a}}$. Twenty PSTs' answers agreed that there was only one fraction between $\frac{2}{5}$ and $\frac{4}{5}$, and three decimals between 0.4 and 0.8 . Most of their answers were followed by presenting a mathematical technique. For instance, one PsT wrote as follows:

I think the pupils' answers are correct, because we know [that] the only fraction between $\frac{2}{5}$ and $\frac{4}{5}$ is $\frac{3}{5}$, meanwhile decimals between 0.4 and 0.8 are $0.5,0.6$, and 0.7 ( $\mathrm{IS}_{7 \mathrm{a}}$ ).

IS $_{7}$ just applied the mathematical technique of ordering fractions and decimals because she just showed that both fractions and decimals in the tasks were already in the format of fractions with a common denominator and a one-digit decimal. Meanwhile, only three PSTs' written answers indicate that there are many numbers between two fractions but not between two decimals, and other four PSTs' written answers indicate that there are many numbers between two decimals but not between two fractions. This is illustrated by $\mathrm{IS}_{13 a}$ on his written answer

I think if the pupil answers that there is a number between $\frac{2}{5}$ and $\frac{4}{5}$, namely $\frac{3}{5}$, it means that his understanding of fractions is correct. Meanwhile, if he thinks that there are three numbers between 0.4 and 0.8 , it means his understanding of decimals is still not sufficient because decimals are different from fractions. If he thinks after 0.4 there are $0.5,0.6,0.7$, and then 0.8 , it is not correct because there are also $0.51,0.52$, etc. (IS $13 a)$. 
$\mathrm{IS}_{13 \mathrm{a}}$ considered that fractions and decimals were two different kinds of number. He did not realise (or use) that a fraction such as $\frac{2}{5}$ has the same value as 0.4 .

Two Indonesian PSTs provided a didactical technology for pupils' misconceptions: the pupils just apply their common and simple mathematical technique of ordering natural numbers to ordering fractions and decimals. For example, $I_{13 b}$ wrote on her worksheet as

From the pupils' answers, I think their answers are based on their simple understanding because between $\frac{2}{5}$ and $\frac{4}{5}$, there is $\frac{3}{5}$ since they have a common denominator, and there are 3 numbers between 0.4 and 0.8 because they are in the same form that is a one-digit decimal $\left(\mathrm{IS}_{13 \mathrm{~b}}\right)$.

Even though $\mathrm{IS}_{13 \mathrm{~b}}$ gave the interpretation behind pupils' misconception, she did not provide any more explanation which indicates that she knows there are infinitely many numbers between them.

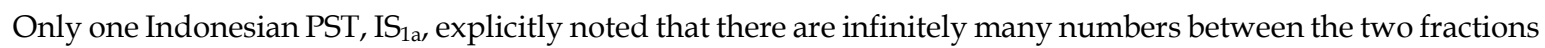
and also between the two decimals. She supported her answers by prolonging fractions and decimals and showing that the tasks are the same, since $\frac{2}{5}=0.4$ and $\frac{4}{5}=0.8$. While, two Indonesian PSTs did not give an answer to the task of type $\mathrm{T}_{\mathrm{a}}$.

\section{The Praxeological Analysis of Danish and Indonesian PSTs' Collective Work}

The Danish and Indonesian PSTs did the collective work after they completed the written answer to the type of task $\mathrm{T}_{\mathrm{a}}$. The discussion focused on the type of didactical task $\mathrm{T}_{\mathrm{b}}$, but this could not be separated from their individual work. We analyse their collaborative praxeologies on the three following categories.

\section{Discrete praxeology: no or limited knowledge to support the praxeological change}

From the a posteriori analysis of Danish PSTs' written answers and their collaborative work, none of them seems to be in this category. This is because all the Danish pairs were actually able to figure out the pupils' misconception on both tasks: that the pupils just considered fractions with a common denominator and one digit decimals, and order them as natural numbers. In fact, the pupils did not see that the given numbers could be converted from fractions to decimals or vice versa, and that they have the same value, e.g. $\frac{2}{5}$ equals to 0.4 .

In contrast, ten Indonesian pairs agreed that there were finitely many numbers between two fractions and also between two decimals. The mathematical technique underlying their answers was to consider the order of fractions or decimals as a simple extension of the ordering of integers. Even though three pairs applied a mathematical technique of changing fractions into decimals or vice versa, they were still trapped by the ordering problem. For instance, $\mathrm{S}_{11 \mathrm{~b}}$ changed $\frac{2}{5}$ to 0.4 and $\frac{4}{5}$ to 0.8 , and then realised that both tasks were the same but with different representations. She proposed that there were also three numbers between two fractions because a fraction, such as 0.5 lying between the two decimals, equals $\frac{1}{2}$, and it is also between the two fractions. In addition, her partner, $\mathrm{S}_{11 \mathrm{a}}$, did not provide any suggestion or question that could lead them to consider other rational numbers between the two rational numbers, but she emphasized a generic didactical technique, organising a classroom discussion without giving any explanation on how pupils' misconceptions might be resolved in such a discussion.

Besides directly instructing pupils to order fractions with a common denominator and order decimals with the same digit, five pairs of Indonesian PSTs in this category suggested a didactical technique of teaching pupils through representing fractions and decimals on number lines. Since they represented fractions and decimals in two different number lines, they could not realise that a fraction, such as $\frac{2}{5}$, would be in the same position as 0.4 if they located both numbers in the same number line. For instance, the following excerpt presents a discussion between $\mathrm{IS}_{15 \mathrm{a}}$ and $\mathrm{IS}_{15 \mathrm{~b}}$ :

IS $_{15 b}:$ How can we explain it with number lines?

Then, $\mathrm{IS}_{15 \mathrm{a}}$ draws a number line in the paper and writes 0 in the middle.

$\mathrm{IS}_{15 \mathrm{~b}}$ : I don't understand it. (points her written answer presented in Figure 2a)

$\mathrm{IS}_{15 \mathrm{a}}$ : Hah! Why is that?

$\mathrm{IS}_{15 \mathrm{~b}}$ : That's why I don't understand. What if it is represented into a number line? Or $\frac{1}{5}$ is written under the line. Or like this, $\frac{1}{5}, \frac{2}{5}, \frac{3}{5}$, and $\frac{4}{5}$. (write those fractions under the number line, presented in Figure $2 \mathbf{b}$ ).

$\mathrm{IS}_{15 \mathrm{a}}$ : Here is 0 . (points the left edge of the number line, presented in Figure $\mathbf{2 b}$ ) 


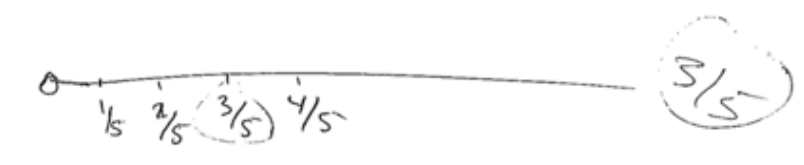

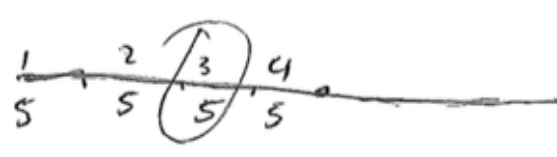

(a)

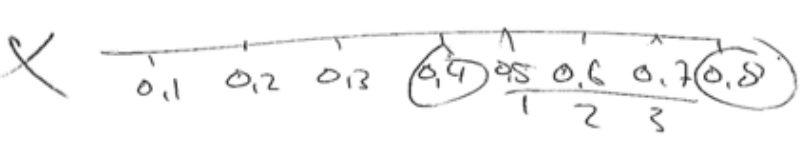

(b)

Figure 2. a. IS $S_{15 b}$ 's written answer b. Separated number line representations for fraction and decimal tasks

$\mathrm{IS}_{15 \mathrm{~b}}$ : Oh yes, then the answer is 1 . [Between] $\frac{2}{5}$ [and] $\frac{4}{5}$ is 1 , [and] this is only $\frac{3}{5}$.

$\mathrm{IS}_{15 \mathrm{a}}$ : Yes, that is correct. Let we agree on that (Then, both of them laugh). How about 0.4 and 0.8 ?

$\mathrm{IS}_{15 \mathrm{a}}$ : If it is represented in a number line.

$\mathrm{IS}_{15 \mathrm{~b}}$ : Correct. There are also 3 numbers.

(Then, $\mathrm{IS}_{15 \mathrm{~b}}$ writes another number line under the previous one, presented in figure $2 \mathrm{~b}$, and shows that there are also 3 decimals between 0.4 and 0.8 ).

Even though they succeed to represent fractions and decimals into two separate number lines, they do not figure out that between two consecutive fractions or decimals, one can always find other fractions or decimals (a technology that can lead to the theoretical result of the density of rational numbers). The representations of fractions with a common denominator and decimals with one-digit lead them to consider the mathematical task as more on the order of integers than on the density of rational numbers.

Another interesting finding is from the discussion of $\mathrm{IS}_{4 \mathrm{a}}$ and $\mathrm{IS}_{4 \mathrm{~b}}$. They agreed that they would teach pupils based on how the textbooks explain the techniques of ordering fractions and decimals, but they might not have been aware that the tasks in the textbooks just focus on ordering some given fractions and decimals, not on the set of numbers between given numbers. For this pair, direct instruction based on the textbooks is a general strategy to teach mathematics.

\section{Discrete-denseness praxeology: insufficient knowledge to support praxeological change}

Two Danish pairs are placed in this category. The reason to put them here is their difficulties to synthesise their thoughts about how many numbers there are between two rational numbers. For instance, in one moment in the beginning of the discussion $\mathrm{DS}_{1 \mathrm{~b}}$ stated that there were more numbers between $\frac{2}{5}$ and $\frac{4}{5}$, but in the end her partner and herself agreed that there was only one number between the two fractions. It seems like they do not have consistent answers to the same task.

Even though the two pairs were not really consistent to the density property of rational numbers, they still suggested some potential didactical techniques to show that both tasks are the same. The first didactical technique is based on a contextual problem, called a pizza experiment discussed by $\mathrm{DS}_{1 \mathrm{a}}$ and $\mathrm{DS}_{1 \mathrm{~b}}$. The idea is to link decimals, fractions, and percentages.

We could change the decimals to percentages and get $40 \%$ and $80 \%$. Then, we could ask them to remove $40 \%$ of the pizza and $\frac{2}{5}$ of the pizza. Then, we could help them understand that they have the same value even though they have different notations $\left(D_{1}\right)$.

They know well that the tasks are the same, and there must be the same numbers in between, but they do not provide any mathematical and didactical justification that there are infinitely many numbers between the two

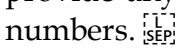

Another example is from the discussion of $\mathrm{DS}_{9_{a}}$ and DS $9 \mathrm{~b}$. Their collaborative work also focused on showing the two tasks are the same. DS $9 \mathrm{~b}$ reflected what they experienced during a practicum at the teacher training.

Pupils have only learned about fractions and decimals separately. There has not been such a link between the two, which can be quite important for the essential understanding of what fractions are. I remember that in practicum we used a specific application for IPad that is called virtual manipulatives which show with the exact same shapes/figures that one third 
corresponds to zero point three three three.... And then the bars are equal in size so you can get them as decimals, fractions and percentages $\left(\mathrm{DS}_{9 \mathrm{~b}}\right)$

$\mathrm{DS}_{9 \mathrm{~b}}$ gave a technological discourse on the necessity to recognise both representations, fractions and decimals as pertaining to rational numbers. This could be supported by using an appropriate media, such as IPad or computer technology, to show that $\frac{1}{3}$ equals to $0, \overline{3}$, but she did not try to link this knowledge to justify that there are infinitely many numbers between them.

Meanwhile, five Indonesian pairs gave inconsistent answers when asked how many numbers there are between two rational numbers. Four of those pairs seem to agree that there is only a fraction between $\frac{2}{5}$ and $\frac{4}{5}$, but many decimals between 0.4 and 0.8 . For instance, In the discussion IS $_{13 \mathrm{a}}$ said that there was only $\frac{3}{5}$ between the two fractions, because after the numerator 2 , it had to be an integer, and that was 3 . It seems that his prior praxeologies of natural numbers lead to the misconception of fractions, and he did not use, for instance, that a mathematical technique of prolonging a fraction by multiplying each numerator and denominator by an integer. Meanwhile, for the decimal task, IS $_{13 a}$ argued

Pupils understanding is not yet stable. [They] still lack of understanding about decimals because after 0.4 there are still $0.41,0.42$, etc. Aren't there? It depends on the numbers of digits behind the comma, but more often there are 3 digits behind the comma...( $\left.\mathrm{IS}_{13 a}\right)$.

$\mathrm{IS}_{13 \mathrm{a}}$ seems to believe that decimals were more flexible than fractions (a possible technology to justify his answer), as he could easily identify many numbers between two decimals through a mathematical technique of putting some 0 s digits behind the comma. He was more dominant in sharing his mathematical and didactical ideas, so that his partner, $\mathrm{IS}_{13 \mathrm{~b}}$, did not give many contributions to construct other possible techniques and technological discourse. $\mathrm{IS}_{13 \mathrm{~b}}$ just relayed what she had written for the question a that the pupils just view the mathematical task based on their simple knowledge of ordering fractions with a common denominator and decimals according to their digits.

One pair in this category, group 16, changed their knowledge from considering many to few numbers between two fractions and two decimals. In the beginning of the discussion, $\mathrm{IS}_{16 \mathrm{a}}$ asked $\mathrm{IS}_{16 \mathrm{~b}}$ about a fraction, $\frac{2.5}{5}$, whether it could be between $\frac{2}{5}$ and $\frac{4}{5}$, so there were many fractions could be written by the numerators from 2.1 until 3 and then 3.1 and so on. IS $_{16 \mathrm{~b}}$ found these weird, because a number was written as a fraction and also as a decimal. She realised that 2.5 equals to $2+\frac{1}{2}=\frac{5}{2}$, but she then ignored the denominator. She could not find a correct fraction representation for $\frac{2.5}{5}$ and supposed $\frac{5}{2}$ be the result, and this fraction was not in between $\frac{2}{5}$ and $\frac{4}{5}$. IS 16 also agreed with IS $_{16 \mathrm{~b}}$ 's explanation, without verifying that mathematical technique. Finally, they agreed to instruct the pupils through the mathematical technique of the order of fractions. Then, it was also observed in the discussion on the decimal task. IS $_{16 a}$ considered many decimals between 0.4 and 0.8 , but he was not so sure with his idea and lacked support from his partner. In this case, $\mathrm{IS}_{16 \mathrm{a}}$, a PsT who has potential praxeological change, was unable to maintain his idea because of less technological means. He could not explain why such a fraction, $\frac{2.5}{5}$, can represent a number between the two fractions.

\section{Denseness praxeology: Sufficient knowledge to support praxeological change}

Thirteen Danish pairs agreed that there are more than just one number between the two fractions and three numbers between the two decimals. They stated clearly during the discussion that there are many numbers between them, and seven of them said that there are infinitely many numbers. For instance, $\mathrm{DS}_{2 \mathrm{~b}}$ first said

There are a lot! There are a lot of numbers between them. There are, for example, complex numbers and much more between them $\left(\mathrm{DS}_{2 \mathrm{~b}}\right)$.

Actually, the example of complex numbers is not appropriate because they do not belong to the numbers pupils know and cannot be ordered consistently. It seems that he just provided an example that he did not really know well. For a further explanation, he argued

...the numbers are the same. They are only written in different notations. This way we see that there are many other numbers in between. There are also decimal numbers. There are infinitely many numbers $\left(\mathrm{DS}_{2 \mathrm{~b}}\right)$.

In fact, knowing both tasks are the same becomes one technological discourse to grasp the density property of rational numbers. 
The two most common didactical techniques suggested by the Danish pairs, are to teach pupils through converting fractions to decimals and sometimes vice versa (12 pairs), and to represent fractions and decimals in a number line (9 pairs). One technological discourse underlying the idea of conversion is to let pupils work more flexibly with rational numbers. For example, $\mathrm{DS}_{4 \mathrm{~b}}$ said

They have to understand the relation between decimals and fractions such that they can transform the numbers. If they struggle with one of the notations, then they can transform it to the other notation $\left(\mathrm{DS}_{4 \mathrm{~b}}\right)$.

Most of the Danish pairs actually tended to convert fractions to decimals more often than vice versa. It seems that decimal representations are more comfortable to see the density of rational numbers. In addition, most of them connected the didactical technique of a number line representation to conversion, or vice versa. One example comes from the discussion of $\mathrm{DS}_{6}$ as follows:

DS $_{6 a}$ : I (also) think it is fine to start by. It does not seem like they have fully understood some of the things yet, to do one thing at a time. [We] just do fractions to begin with, put those on the number line in relation to each other or what? What do you think?

$\mathrm{DS}_{6 \mathrm{~b}}$ : I do not think it clearly appears if they understand fractions or for.. or well to a certain degree.

$\mathrm{DS}_{6 \mathrm{a}}$ : Since they say there are only three numbers in between here (decimals) and one number (fractions)... I think there is something we have to work with in both cases. The task is fine, but perhaps in two parts, where you first place fractions and then you place the other, and then you place the third and then possibly a joint all in one.

$D_{6 b}$ : Yes, and then start with a low level of complexity and then mix it together and have different representations.

$\mathrm{DS}_{6 \mathrm{a}}$ : And then we could us it in the future lessons as a tool. The number line they have made, make a joint one or something that could be hung on a larger piece of paper in the class.

$\mathrm{DS}_{6 \mathrm{~b}}$ : I just came to think that we could also work with conversion from decimal numbers to fractions and vice versa.

$\mathrm{DS}_{6 \mathrm{a}}$ : Yes.

$D_{6 b}$ : So they really get to understand numbers can be represented in different ways but still have the same value.

From the excerpt, it seems that in the beginning they would like to present both tasks, fractions and decimals, in two different number lines. The idea is to avoid the complexity of the tasks, but it also challenges them to realise that both tasks are the same when presented on a number line. In addition, providing a classroom activity to let the pupils use different representations, decimals, fractions, and also possible percentages, will lead them to the conversion of representations of rational numbers because they need to put a same value of numbers but different representations in the same exact position. This kind of mathematical activities can support pupils' praxeological change from seeing numbers as part of a discrete set (integers), to seeing them as dense sets.

Two Danish pairs proposed a didactical technique that might be based on the arithmetic mean, but they did not present detailed explanation on how they found it. For instance, $\mathrm{DS}_{2 \mathrm{~b}}$ explained

We could also write $\frac{2.5}{5}$ between $\frac{2}{5}$ and $\frac{3}{5}$. They correspond to the same values. Those numbers that they thought were the numbers in between the decimals (DS $2 \mathrm{~b})$.

It seems that $\mathrm{DS}_{2 \mathrm{~b}}$ tried to confirm that $\frac{2.5}{5}$ is a number that should be in between two fractions as well as decimals. For a further discussion, he provided a technological discourse behind the common principle on choosing rational number representations because some numbers were prettier to write in fractions than decimals, or vice versa. The reason was that some numbers could only be written precisely using fraction notations such as $\frac{1}{3}$.

Another common didactical technique is to embed the mathematical tasks into contextual situations, discussed by three pairs in this category. The contextual situations presented by PSTs sometimes seem not to be precise didactical praxeologies to teach the density of rational numbers. They tend to focus on a pedagogical aim that the pupils engage in the activity. For instance, DS $_{5 \mathrm{~b}}$ suggested to doing an experiment of pouring one jug of water into five cups. She proposed to use a cup with $200 \mathrm{ml}$ and a jug of 1 litre of water. The question given to the pupils was how many times could you pour water into the cups? Her idea is to let the pupils consider that pouring water into 2 and 4 cups is similar to $400 \mathrm{ml}$ and $800 \mathrm{ml}$ respectively. This activity supports the pupils to know about equivalent values of two different rational number representations, decimals and fractions, but does not suffice to bring out the concept of denseness. 
In contrast, only one Indonesian pair, $\mathrm{IS}_{1 \mathrm{a}}$ and $\mathrm{IS}_{1 \mathrm{~b}}$, can be placed in this category. In the beginning, only IS $\mathrm{S}_{1 \mathrm{a}}$ considered that there are infinitely many numbers between the two decimals and the two fractions. While, IS ${ }_{1 b}$ stated in her worksheet that she agreed with the pupils' answers, and explains it based on ordering fractions and decimals by "counting".

During the collaborative work, $\mathrm{IS}_{1 \mathrm{a}}$ dominated the discussion, and she confidently stated that there are many numbers between two fractions and also two decimals, as infinitely many numbers. One of her technological discourse is based on equivalent value like 0.4 is equal to $0.400000 \ldots$ and so on, so between 0.4 and 08 , there are many numbers. To teach the pupils, she suggested two didactical techniques. First, she provided a contextual situation of dividing a cake, that if one divides a cake into two equal parts, each of part is a half, then one can do it again by dividing a half into more pieces and so on. The second one is to represent fractions and decimals on number lines and then showing that between two fractions or decimals, one can find another number. It seems that she indirectly tries to employ the technological idea behind the arithmetic mean (Brousseau 1997; Vamvakoussi, \& Vosniadou, 2004).

\section{DISCUSSION}

The overall aim of this study is to present the idea of praxeological change which describes the need for changing practical and theoretical knowledge at some critical points. This idea is applied to a comparative case study of the Danish and Indonesian PSTs. We now summarise the major findings of this study as explicit partial answers to the three research questions, and point out implications for pre-service teacher training related to the rational numbers.

The differences between Danish and Indonesian PSTs' mathematical and didactical knowledge $\left(\mathrm{RQ}_{1}\right)$ are clearly indicated by their individual and collaborative work. There is a wide gap between them, both at the practical and theoretical level, and both mathematically and didactically. The basic difference is that the Danish pairs are more successful with applying the mathematical technique of converting fractions to decimals and vice versa. It leads them to perceive that the pairs of numbers, involving fractions and decimals, have the same value, so the theory of infinitely many numbers between two fractions as well as between two decimals could be achieved. Meanwhile, the Indonesian pairs assume that fractions and decimals are two different kinds of number. They tend to use their pre-established knowledge about whole numbers on both kinds, and apply the mathematical technique of ordering by counting, which amounts to the misconceptions on rational numbers that have also been observed in the study of Widjaya et al. (2008), in the case of decimals. This explains the inability of the Indonesian PSTs to propose sufficient mathematical praxeologies for the density of rational numbers (Vamvakoussi \& Vosniadou, 2004). Therefore, acquiring the concept of density is not only a slow process for the Indonesian PSTs, but it can be impossible to achieve for most of them by the end of the teacher training programme. The root of the misconception likely lies with the insufficient instruction in most Indonesian schools (e.g., Revina \& Leung, 2018). The school experience is likely limited to working with procedural techniques. This knowledge is then used by the Indonesian PSTs without realise the need for the praxeological change both on the practices and theory related to order of numbers (figure 1); it is not rectified by the instruction during their studies in the teaching training institution.

Through categorising PSTs' collaborative work into three categories; discrete, discrete-denseness, and denseness praxeologies, it can be seen to what extent PSTs themselves have realised the praxeological change $\left(R_{2}\right)$. PSTs in the first category, as most of the Indonesian pairs, did not realise the need for students' praxeological change although they master some potentially relevant mathematical techniques, like converting fractions to decimals or vice versa. One main reason is their limited mathematical knowledge on subsets of rational numbers (Vamvakoussi \& Vosniadou, 2004), and their tendency to apply the counting order from natural numbers directly to rational numbers. PSTs with discrete-denseness praxeologies mostly realize that fractions and decimals are different representations of the same numbers. They tend to change their praxeologies when they work with decimals and fractions at the same time. This is because finding "many" numbers between two given numbers is much easier for them if they work with decimals than they work with fractions. They just need to add 0s digits after comma. As in other studies (Vamvakoussi \& Vosniadou, 2010; Vamvakoussi et al., 2011) we have seen here that the type of the interval endpoints affects their judgment and the mathematical techniques they propose, and also the corresponding technology. In the last category, in which we can say that PSTs have realised the need for conceptual change in the fictitious pupils, we find most of the Danish pairs. One reason for that is that most of them individually recognise that the two mathematical tasks are essentially the same, and they bring this knowledge to the collaborative work. Using the mathematical technique of converting fractions to decimals or vice versa, they show the equivalent value of fractions and decimals such as $\frac{1}{2}=0.5$. Indeed, one can say that to achieve the denseness properties of rational numbers, one needs to have firm practical knowledge of equivalence class of rational numbers $(\mathrm{Wu}, 2014)$. In the one Indonesian pair whose collaborative praxeology can be put in the denseness 
category, only one of the PSTs $\left(\mathrm{SI}_{1 \mathrm{a}}\right)$ had sufficient individual mathematical knowledge but she was able to convince her partner to accept the infinity of numbers between the two fractions and decimals.

Answering the third research question related to the PSTs' collective work supporting pupils' praxeological change $\left(\mathrm{RQ}_{3}\right)$, it is obvious that the gap between Danish and Indonesian PSTs' mathematical praxeologies affects the didactical praxeologies they are able to develop, even in pairs. The Danish PSTs have more solid mathematical knowledge about rational numbers than the Indonesian PSTs. Most of the Danish pairs consider (infinitely) many rational numbers between two fractions and two decimals because they recognise the equivalent value like 0.4

equals $\frac{2}{5}$ and use it to propose adequate didactical praxeologies. Most of Danish pairs employ two specific didactical techniques: emphasize conversion between decimals and fractions, and use the representations of both kinds of number on a number line. They attempt to combine the two tasks into a situation that can support the pupils to conceive several properties of rational numbers, not only density but also others such as multiple representations and equivalent classes of rational numbers. Meanwhile, the Indonesian pairs try to solve the problem by principles used in standard tasks on ordering given fractions and decimals. Some of them also try to use number line representations, while they locate fractions and decimals in separate number lines; they also do not really make use of the fact that any line segment contains infinitely many points (Vamvakoussi, 2017). In addition, a lack of technological discourse or questioning a proposed didactical technique leads to limitations in further elaborations of didactical techniques. Number line representations seem to be ineffective to support Indonesian PSTs' praxeological change because they still basically rely on locating natural numbers when working on rational numbers. In fact, the linear model representations of number lines employed by the two groups do not show a similar result to support pupils to develop the density of rational numbers, and they really depend on mathematical knowledge the PSTs have. While, proposing an activity involving contextual situations may support pupils to learn about equivalent representations of rational numbers, it is not enough to develop pupils' knowledge about the density (McMullen et al., 2015).

It certainly appears from these results that there is a need for the teacher training institutions to focus on the important challenges related to praxeological change from natural to rational numbers, not only in terms of theory (notions, "concepts" and so on) but also at the level of basic practice and in the relationships between them (Figure 1).

\section{CONCLUDING REMARKS}

Praxeological change is needed at critical points of learning mathematics, when it does not suffice to smoothly extend "old" mathematical praxeologies. If teachers are struggling with an incomplete praxeological change themselves, they will find it difficult to support pupils' praxeological change. Through the Danish and Indonesian case, we present to what extent the need for such praxeological change is observed both in and by PSTs during their individual and collective work on a task related to the density of rational numbers.

This change, indeed, involves both practice and theory (figure 1) while many previous studies address the changes of practical and theoretical "concepts" separately through the lens of conceptual change, but the point of a praxeological analysis is to consider these levels as closely related. Without putting aside the existing theory of conceptual change, praxeological change can provide a more solid framework for learning the change of human knowledge. Meanwhile, this study only focuses on the use of HTT as a tool, but we may recommend for further research to apply it in teacher education to raise the mathematical needs PSTs have when dealing with school mathematics to support them problematize the mathematical and didactical knowledge they will have to teach.

\section{ACKNOWLEDGEMENTS}

I would like to thank the Ministry of Research, Technology, and Higher Education of the Republic of Indonesia for funding this research under the grant no.102.7/E4.4/2015.

\section{REFERENCES}

An, S., Kulm, G., \& Wu, Z. (2004). The pedagogical content knowledge of middle school, mathematics teachers in China and the US. Journal of Mathematics Teacher Education, 7(2), 145-172. https:/ / doi.org/10.1023/B:JMTE.0000021943.35739.1c

BAN-PT. (2017). Directorate result of study programme accreditation [Direktori hasil akreditasi program studi]. Retrieved from https://banpt.or.id/direktori/prodi/pencarian_prodi

Barbé, J., Bosch, M., Espinoza, L., \& Gascón, J. (2005). Didactic restrictions on the teacher's practice: The case of limits of functions in Spanish high schools. In Beyond the apparent banality of the mathematics classroom (pp. 235-268). Springer US. https:/ / doi.org/10.1007/0-387-30451-7_9 
Behr, M. J., Lesh, R., Post, T., \& Silver, E. A. (1983). Rational number concepts. Acquisition of mathematics concepts and processes, 91-126.

Bosch, M., \& Gascón, J. (2014). Introduction to the anthropological theory of the didactic (ATD). In A. BiknerAhsbahs \& S. Prediger (Eds.), Networking of Theories as a Research Practice in Mathematics Education (pp. 6783). Switzerland: Springer International Publishing. https:// doi.org/10.1007/978-3-319-05389-9_5

Brousseau, G. (1997). Theory of didactical situations in mathematics. Dordrecht: Kluwer Academic Publishers.

Chevallard, Y. (1992). Fundamental concepts in didactics: Perspectives provided by an anthropological approach. In R. Douady \& A. Mercier (Eds.), Research in Didactique of Mathematics. Selected papers (pp. 131-167). Grenoble, France: La Pensée sauvage.

Chevallard, Y. (1999). L'analyse des pratiques enseignantes en théorie anthropologique du didactique. Recherches en Didactique des Mathématiques, 19(2), 221-266.

Chevallard, Y. (2006). Readjusting didactics to a changing epistemology. European Educational Research Journal, 6(2), 131-134. https:/ / doi.org/10.2304/ eerj.2007.6.2.131

Chevallard, Y. (2007). Steps towards a new epistemology in mathematics education. In M. Bosch (Eds.), Proceedings of the IV congress of the European society for research in mathematics education (pp. 21-30). Barcelona, Spain: FUNDEMI-IQS.

Christou, K. P. (2015). Natural number bias in operations with missing numbers. ZDM Mathematics Education, 47(5), 747-758. https://doi.org/10.1007/s11858-015-0675-6

Depaepe, F., Torbeyns, J., Vermeersch, N., Janssens, D., Janssen, R., Kelchtermans, G., Verschaffel, L., \& Van Dooren, W. (2015). Teachers' content and pedagogical content knowledge on rational numbers: A comparison of prospective elementary and lower secondary school teachers. Teaching and Teacher Education, 47, 82-92. https:/ / doi.org/10.1016/j.tate.2014.12.009

Durand-Guerrier, V., Winsløw, C., \& Yoshida, H. (2010). A model of mathematics teacher knowledge and a comparative study in Denmark, France and Japan. Annales de Didactiques et de Sciences Cognitives, 15, 141166.

Durkin, K., \& Rittle-Johnson, B. (2015). Diagnosing misconceptions: Revealing changing decimal fraction knowledge. Learning and Instruction, 37, 21-29. https:/ / doi.org/10.1016/j.learninstruc.2014.08.003

Hill, H. C., Rowan, B., \& Ball, D. L. (2005). Effects of teachers' mathematical knowledge for teaching on student achievement. American Educational Research Journal, 42(2), 371-406. https:/ / doi.org/10.3102/00028312042002371

Ma, L. (1999). Knowing and teaching elementary mathematics. Mahwah, NJ: Lawrence Erlbaum Associates.

McMullen, J., Laakkonen, E., Hannula-Sormunen, M., \& Lehtinen, E. (2015). Modeling the development trajectories of rational number concept(s). Learning and Instruction, 37, 14-20. https:/ / doi.org/10.1016/j.learninstruc.2013.12.004

Ministry of Higher Education and Science. (2015). The Danish teacher education programme: B.Ed. programme for primary and lower secondary schools. Copenhagen: Danish Agency for Higher Education. Retrieved 04 October 2017 from https://ufm.dk/en/education-and-institutions/higher-education/university-colleges/ university-college-educations/bachelor-of-education/b-ed-programme-for-primary-and-lower-secondaryschools.pdf

Mullis, I. V. S., Martin, M. O., Foy, P., \& Hooper, M. (2016). TIMSS 2015 International Results in Mathematics. Retrieved from Boston College, TIMSS \& PIRLS International Study. http:/ / timssandpirls.bc.edu/timss2015/international-results/

OECD. (2016), PISA 2015 Results (Volume I): Excellence and Equity in Education, PISA, OECD Publishing, Paris. http://dx.doi.org/10.1787/9789264266490-en

Prediger, S. (2008). The relevance of didactic categories for analysing obstacles in conceptual change: Revisiting the case of multiplication of fractions. Learning and instruction, 18(1), 3-17. https:/ / doi.org/10.1016/j.learninstruc.2006.08.001

Prodi PGSD UR. (2017). The structure of curriculum for elementary school teacher education program [Kurikulum berbasis KKNI tahun 2014: Struktur kurikulum program studi pendidikan guru sekolah dasar]. Retrieved from http://pgsd.fkip.unri.ac.id/kurikulum/

Putra, Z. H. (2016). Collective aspects of pre-service lower secondary teachers' knowledge on density of rational numbers. In M. Achiam \& C. Winsløw (Eds.), Educational Design in Math and Science: the Collective Aspect (pp. 53-61). Copenhagen, Denmark: University of Copenhagen. 
Putra, Z. H., \& C. Winsløw (in press). A framework for a comparative study of pre-service elementary teachers' knowledge of rational numbers. Educaçao Matemática Pesquissa.

Rasmussen, J., \& Bayer, M. (2014). Comparative study of teaching content $\mathrm{n}$ teacher education programmes in Canada, Denmark, Finland, and Singapore. Journal of Curriculum Studies, 46(6), 798-818. https:// doi.org/10.1080/00220272.2014.927530

Revina, S., \& Leung, F. K. S. (2018). How the Same Flowers Grow in Different Soils? The Implementation of Realistic Mathematics Education in Utrecht and Jakarta Classrooms. International Journal of Science and Mathematics Education, 1-25. https:/ / doi.org/10.1007/s10763-018-9883-1

RISTEKDIKTI. (2016). A guideline for preparing a curriculum of higher education [Panduan penyusunan kurikulum pendidikan tinggi]. Jakarta: Direktorat Jenderal Pembelajaran dan Kemahasiswaan Kementerian Riset Teknologi dan Pendidikan Tinggi.

Rodríguez, E., Bosch, M., \& Gascón, J. (2008). A networking method to compare theories: metacognition in problem solving reformulated within the Anthropological Theory of the Didactic. ZDM Mathematics Education, 40(2), 287-301. https:/ / doi.org/10.1007/s11858-008-0094-z

Stacey, K., Helme, S., Archer, S., \& Condon, C. (2001). The effect of epistemic fidelity and accessibility on teaching with physical materials: A comparison of two models for teaching decimal numeration. Educational Studies in Mathematics, 47(2), 199-221. https:/ / doi.org/10.1023/ A:1014590319667

Vamvakoussi, X., Christou, K. P., Mertens, L., \& Van Dooren, W. (2011). What fills the gap between discrete and dense? Greek and Flemish students' understanding of density. Learning and Instruction, 21(5), 676-685. https://doi.org/10.1016/j.learninstruc.2011.03.005

Vamvakoussi, X., \& Vosniadou, S. (2004). Understanding the structure of the set of rational numbers: A conceptual change approach. Learning and Instruction, $453-467$. https:/ / doi.org/10.1016/j.learninstruc.2004.06.013

Vamvakoussi, X., \& Vosniadou, S. (2010). How many decimals are there between two fractions? Aspects of secondary school students' understanding of rational numbers and their notation. Cognition and Instruction, 28(2), 181-209. https:/ / doi.org/10.1080/07370001003676603

Van Hoof, J., Verschaffel, L., \& Van Dooren, W. (2015). Inappropriately applying natural number properties in rational number tasks: Characterizing the development of the natural number bias through primary and secondary education. Educational Studies in Mathematics, 90(1), 39-56. https:// doi.org/10.1007/s10649-0159613-3

Widjaja, W., Stacey, K., \& Steinle, V. (2008). Misconceptions about density of decimals: Insights from Indonesian pre-service teachers' work. Journal for Science and Mathematics Education in Southeast Asia, 31(2), 117-131.

Winsløw, C., \& Durand-Guerrier, V. (2007). Education of lower secondary mathematics teachers in Denmark and France: A comparative study of characteristics of the systems and their products. Nordisk Matematikkdidaktikk, 12(2), 5-32.

$\mathrm{Wu}$, H. (2014). Fractions, decimals, and rational numbers. Retrieved 05 December 2017 from https:/ / math.berkeley.edu/ wu/NMPfractions.pdf

Zhou, Z., Peverly, S. T., \& Xin, T. (2006). Knowing and teaching fractions: A cross-cultural study of American and Chinese mathematics teachers. Contemporary Educational Psychology, 31(4), 438-457. https://doi.org/10.1016/j.cedpsych.2006.02.001

\section{http://www.ejmste.com}

